Institute of $\mathbf{F}_{\text {ood and }} \mathbf{A}$ gricultural $\mathbf{S}_{\text {ciences }}$

\title{
Florida Fresh: Grapefruit ${ }^{1}$
}

Jennifer Hillan²

You can buy delicious fruits and vegetables at farmers' markets. You can also ask the person who grew it how to eat it! Because the produce is locally grown, it's fresh and costs less than at the supermarket. Enjoy some of your favorites or try something new! To find a farmers' market in your area, call your county Extension office or visit the Florida Department of Agriculture's web site: www.fl-ag.com/farmmkt/city.htm.

\section{History and Facts}

Grapefruit got it's name

from the way it grows on trees in clusters, like grapes.

Florida grows more grapefruit than anywhere else in the world!

The antioxidant lycopene gives pink and red grapefruit their color. Eating foods high in lycopene may help reduce the risk of heart disease and some types of cancer.

\section{Half of a Florida grapefruit} gives us about half of the vitamin $\mathrm{C}$ we need each day!

\section{Availability}

October through July

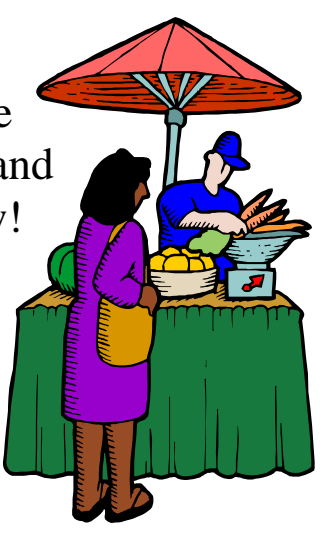

\section{Selection}

Choose grapefruit that are smooth, firm, and feel heavy for their size. The skin may have shades of yellow, white, pink or green. At the market, they are all ripe and ready to eat!

\section{Storage}

Store grapefruit uncovered in the refrigerator crisper. Eat within two weeks.

\section{Uses \& Preparation}

Rinse and scrub outside of grapefruit before cutting. Enjoy grapefruit halves with breakfast or as a quick snack. Add grapefruit segments to tossed salads or fruit salads.

Cut and squeeze grapefruit for a refreshing and healthful drink. Grapefruit loses some vitamin C after it's cut, so make only the amount of juice that you will drink right away.

1. This document is FCS8678, one of a series of the Department of Family, Youth and Community Sciences, Florida Cooperative Extension Service, Institute of Food and Agricultural Sciences, University of Florida. Publication date: July 2002. Reviewed by Isabel Valentín-Oquendo, MS, RD, LD/N. Please visit the EDIS Web site at http://edis.ifas.ufl.edu

2. Jennifer Hillan, MSH, RD, LD/N, Coordinator, Educational/Training Programs, Department of Family, Youth and Community Sciences, Cooperative Extension Service, Institute of Food and Agricultural Sciences, University of Florida, Gainesville, 32611. 


\section{Nutrient Facts}

* Excellent source of vitamin $\mathrm{C}$ and fiber

* Supplies potassium, magnesium, and folate

* Fat, cholesterol, and sodium free

\section{What are Organically Grown Foods?}

Organically grown means that a food was grown without synthetic (man-made) pesticides or fertilizers. Natural pesticides and fertilizers were used instead. Organic and non-organic foods are similar in taste and nutritional value. However, organic foods usually cost more.

\section{Four Star Citrus Ambrosia}

\section{Serves 4}

grated peel of $1 / 2$ tangerine

1 cup vanilla or lemon lowfat yogurt

2 tangerines, rinsed, peeled, cut into sections

2 oranges, rinsed, peeled, cut into sections

1 grapefruit, rinsed and segmented

$2-1 / 2$ tablespoons flaked coconut

Stir tangerine peel into yogurt. Place fruit into four small bowls. Top with yogurt and coconut. Garnish with fresh mint leaves, if desired.

\section{Grapefruit Surprise}

Serves 4

2 grapefruit, rinsed and segmented

2 cups lowfat yogurt

$1 / 2$ cup wheat germ

Place grapefruit in four small bowls. Top with yogurt and wheat germ and enjoy!

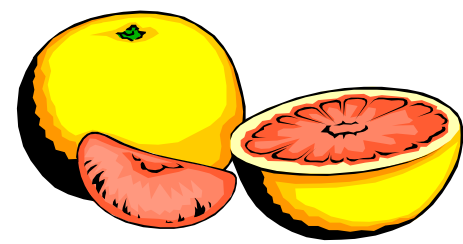

Grapefruit Juice and
Medications
Grapefruit juice may interact with
some prescription medications, such
as some drugs used to treat anxiety,
depression, high blood pressure, and
high cholesterol. Ask your pharmacist
if grapefruit juice affects any of your
medications.
If you're currently
drinking grapefruit
juice and taking
prescription
medications, talk to
your pharmacist or
doctor before you
make any changes.

\section{Florida Tossed Salad}

Serves 4

4 cups spinach or other salad greens, rinsed and torn into small pieces

$1-1 / 2$ grapefruit, rinsed and segmented

$1 / 2$ small red onion, thinly sliced

$1 / 4$ cup sesame seeds or chopped walnuts (optional)

Dressing:

juice from $1 / 2$ grapefruit

2 tablespoons vegetable oil

1 teaspoon honey

1 tablespoon chopped fresh mint or cilantro (optional)

Mix dressing in small bowl and set aside. In large bowl, combine salad ingredients. Add dressing and toss to coat. 